Natalia Pamuła (D) htrps://orcid.org/0000-0003-3399-805X

\author{
Ośrodek Studiów Amerykańskich \\ Uniwersytet Warszawski \\ e-mail: nm.pamula@uw.edu.pl
}

\title{
CRIPPOWANIE I DEMONTOWANIE. WOKÓł ANTOLOGII DISABILITY AND DISSENSUS: STRATEGIES OF DISABILITY REPRESENTATION AND INCLUSION IN CONTEMPORARY CULTURE
}

\author{
Disability and Dissensus: Strategies of Disability Representation and In- \\ clusion in Contemporary Culture, red. Katarzyna Ojrzyńska, Maciej \\ Wieczorek, Brill, Leiden-Boston 2020, 282 ss.
}

Zredagowana przez Katarzynę Ojrzyńską i Macieja Wieczorka z Uniwersytetu Łódzkiego i wydana w 2020 roku przez Wydawnictwo Brill anglojęzyczna antologia Disability and Dissensus: Strategies of Disability Representation and Inclusion in Contemporary Culture zadaje ciekawe pytanie: czy i w jaki sposób niepełnosprawność wprowadza zamęt w obszar kultury? I czy zamęt ten może przełożyć się na ukształtowanie nowych społecznych konceptualizacji niepełnosprawności? Nie ulega wątpliwości, że celem Ojrzyńskiej i Wieczorka oraz zaproszonych przez nich do współpracy polskich i zagranicznych autorek i autorów, m.in. Jolanty Rzeźnickiej-Krupy, Doroty
Krzemińskiej, Małgorzaty Sugiery, Jamesa Caseya, Marii Tsakiri, Wiktorii Siedleckiej-Dorosz, Lena Collinsa, jest ukazanie, iż kultura posiada moc pozwalającą zmienić społeczne rozumienie niepełnosprawności z medycznego na społeczne $i$ antydyskryminacyjne. Wszyscy oni wydają się podpisywać pod postawioną we wstępie Ojrzyńskiej i Wieczorka tezą, że kulturowe czy - precyzyjniej - filmowe, teatralne i literackie reprezentacje niepełnosprawności, gdy są tworzone przez osoby niepełnosprawne lub wyrażające ideały studiów o niepełnosprawności (disability studies), kontestują społeczne przekonania dotyczące różnorodności, nienormatywności i ciała. 
Niepełnosprawność jest kondycją czy doświadczeniem z gruntu politycznym: nie pasuje do świata zastanego (zaprojektowanego zwykle $\mathrm{z}$ myślą o większości bez niepełnosprawności) oraz obnaża normy i mechanizmy wykluczenia. Jest uwikłana w relacje władzy, a raczej - gdy skorzystać z niej jako kategorii analitycznej - obrazuje, kto i na jakiej zasadzie ma dostęp do społecznych zasobów (takich jak np. edukacja - zarówno ta szkolna, jak i wyższa, zatrudnienie, opieka medyczna wysokiej jakości itd.), kto jest uważany za obywatela i jakie prawa mu przysługują. Ale czy reprezentacje niepełnosprawności, nawet wtedy, gdy odrzucają medyczne, a więc patologizujące lub moralne czy magiczne rozumienie niepełnosprawności ${ }^{1}$ i podążają za społecznym modelem niepełnosprawności², a więc tym, który ujmuje ją jako rezultat społecznej opresji, stają się automatycznie narzędziem zmiany?

We wstępie Ojrzyńska i Wieczorek omawiają zdjęcie łódzkiego muralu przedstawiającego młodą blondwłosą dziewczynę siedzącą na wózku inwalidzkim i spoglądającego na nią muskularnego mężczyznę. Autorzy piszą, że

Moralny lub magiczny model niepełnosprawności to przednowoczesne modele konceptualizowania niepełnosprawności, według których niepełnosprawność to np. znak kary lub nagrody od boga. Zob. D. Goodley, Disability Studies: Interdisciplinary Introduction, SAGE Publications, London 2010.

2 Zob. E. Godlewska-Byliniak, J. Lipko-Konieczna (red.), Niepetnosprawność $i$ spoteczeństwo: performatywna siła protestu, Fundacja Teatr 21, Warszawa 2018. mural ma potencjał polityczny ${ }^{3}$ i dodają, że pokazuje on dziewczynę jako,,seksualnie atrakcyjną kobietę, która aktywnie uczestniczy w przypadkowym, opartym na spojrzeniu, flircie"4. Poza tym wózek inwalidzki nie oznacza tu ,tragedii”, lecz służy jako „narzędzie wyzwalające; jest zarówno funkcjonalne, jak i estetycznie przyjemne do spoglądania"5. Jednocześnie Ojrzyńska i Wieczorek mają rację, gdy piszą, że mural stanowi jasny komunikat, że „niepełnosprawna osoba jest uważana za atrakcyjną wtedy, gdy jej ciało spełnia ogólnie akceptowane normy piękna". Ale podtrzymywanie wąskich norm piękna i atrakcyjności to nie jedyna rzecz, która sprawia, iż proponowany przez mural potencjał polityczny jest dość ograniczony. Autorzy pominęli w swojej analizie ważny wątek: mural uczestniczy w podtrzymywaniu heteronormatywności. I nie chodzi tylko o to, że tak sformułowana przez badaczy interpretacja nie jest intersekcjonalna, ale że nie wskazuje, iż reprezentacje niepełnosprawności może charakteryzować istotne napięcie: mogą być one zarówno wehikułem zmiany, gestem sprzeciwu, jak i narzędziem utrwalającym społeczny status quo. Inaczej mówiąc, mogą być częścią przekazów, które zawierają w sobie treści i emancypacyjne, i konserwatywne - tak jak łódzki mural ${ }^{7}$.

K. Ojrzyńska, M. Wieczorek (red.), Disability and Dissensus: Strategies of Disability Representation and Inclusion in Contemporary Culture, Brill, Leiden-Boston 2020, s. 2.

4 Ibidem.

5 Ibidem.

6 Ibidem.

7 Elizabeth A. Wheeler, amerykańska literaturoznawczyni i badaczka disability studies, 
Ale nawet jeśli książce brakuje czasem rozegrania ambiwalencji, o której pisałam powyżej, bardzo ciekawa wydaje mi się sama jej forma. Wiele artykułów zostało napisanych przez dwie osoby, wiele eksperymentuje $\mathrm{z}$ gatunkiem, jaki stanowi tekst naukowy. Jina B. Kim, amerykańska badaczka studiów o niepełnosprawności, definiuje cripping jako sposób czytania, który ,korzysta z niepełnosprawności jako soczewki pozwalającej krytykowi zwrócić uwagę na to, jak założenia i ideologie wynikające $\mathrm{z}$ pełnosprawnej pozycji kształtują tekst". O kategorii crip i teorii crip $^{9}$ w antologii Disability and Dissensus tak pisze duet Marek Mackiewicz-Ziccardi i Dan Goodley: „,teoria crip szuka możliwości celebrowania nadwyrężającego [kulturowy status quo - przyp. N.P.] potencjału niepełnosprawności"'10. Po-

w HandiLand: The Crippest Place on Earth pisze, iż w amerykańskiej literaturze młodzieżowej niepełnosprawni bohaterowie są zwykle biali, mimo iż niepełnosprawność często się łączy - w kontekście amerykańskim - z innym niż biały kolorem skóry. Autorka thumaczy to niechęcią czytelniczek i czytelników do identyfikacji z więcej niż jedną różnicą. Niepełnosprawność w tym kontekście przyczynia się do utrwalenia normy białego koloru skóry, mimo iż jednocześnie wprowadza nowy typ bohatera i bohaterki literackiej.

8 Jina B. Kim wygłosiła powyższe zdanie podczas wykładu Cripping the Welfare Queen: The Radical Potential of Disability Politics?, 9.10.2020, na platformie Zoom (tłum. własne).

9 Tłumaczenie fragmentu książki Roberta McRuera Crip Theory: Cultural Signs of Disability and Queerness ukaże się w „Tekstach Drugich" w numerze 2/2020.

10 D. Goodley, M. Mackiewicz-Ziccardi, Critical Disability Studies: Sketches from Poland and the $U K$ [w:] K. Ojrzyńska, M. Wieczorek stawiłabym tezę, że tzw. crippowanie może być nie tylko sposobem czytania tekstu, ale też jego tworzenia: podważaniem, nadwyrężaniem często ,,skostniałych" gatunków, eksperymentowaniem $\mathrm{z}$ formą, odsłanianiem się autorów w tekstach. Ciekawy przykład to artykuł "...and we all": The Phenomenon of Theatre 21 Wiktorii Siedleckiej-Dorosz. Wydaje się, że świadomie odrzuca on formułę, jaką jest artykuł naukowy, i stanowi raczej wyznanie miłości do polskiego Teatru 21, w którym grupę aktorską stanowią osoby z zespołem Downa i autyzmem. Tekst Siedleckiej-Dorosz zasługuje na uwagę nie tylko dlatego, że nie jest zainteresowany spojrzeniem „krytycznym” na Teatr 21, ale dlatego, że przedstawia jego historię (zapewne jest to jeden $\mathrm{z}$ pierwszych tego rodzaju zapisów historii Teatru 21 w języku angielskim), śledzi początki, zbiera wypowiedzi osób zaangażowanych w jego działanie. W pewnym sensie jest hołdem i wydobywa to, co w owym teatrze nowatorskie, a na poziomie formalnym dowodzi, że można powiedzieć coś ważnego o przecięciu kultury i polityki, rezygnując $\mathrm{z}$ formuły tekstu naukowego i korzystając z czegoś, co nazwałabym opisem zaangażowanym.

Całkiem tradycyjnie zatytułowany (i wcześniej wspomniany) tekst Marka Mackiewicza-Ziccardiego i Dana Goodleya, pt. Critical Disability Studies: Sketches from Poland and the UK, zarówno dzięki formie, jak i tematowi obrazuje w inny sposób, niż robi to Siedlecka-Dorosz - czym może być crippowanie

(red.), Disability and Dissensus..., op. cit., s. 40 . 
tekstu. Autorzy zderzają dwa głosy i dwie perspektywy: niepełnosprawnego byłego doktoranta disability studies z Polski i brytyjskiego profesora. Celem owego zderzenia nie jest uwydatnienie różnic między nimi, a raczej ukazanie, iż studia o niepełnosprawności to nie wyłącznie teoria, a praktyka, w tym praktyka komponowania tekstu. To tekst utkany z odwołań do klasyków i klasyczek studiów o niepełnosprawności, ale także wprost mówiący o życiowych doświadczeniach i wyborach Mackiewicza-Ziccardiego. Jest to o tyle znaczące, iż duża część studiów o niepełnosprawności poświęcona jest analizie pamiętników osób z niepełnosprawnościami, a same pamiętniki i wspomnienia bywają materiałem wykorzystywanym do badania historii osób z niepełnosprawnościami. Po części tekst Critical Disability Studies: Sketches from Poland and the UK jest i refleksją naukową, i fragmentem memoire'u, i kawałkiem autoetnografii, a przy tym wszystkim dwugłosem. W rezultacie artykuł zamazuje granice między gatunkami, pokazując, w jaki sposób studia o niepełnosprawności mogą stać się życiową praktyką.

W konsekwencji antologia Disability and Dissensus i zawarte w niej teksty, przede wszystkim wspomnianych wyżej dwóch duetów, prowokują do zadania pytania o to, na ile studia o niepełnosprawności - zarówno w nauce polskiej, jak i zagranicznej - mają potencjał nadkruszenia tradycyjnych formuł komponowania tekstów akademickich. Na ile oferują nie tylko nowy temat badania, ale także sposób, w jaki się o nim pisze. W Crip Theory: Cultural Signs of Queerness and Disability, dziś chyba już kanonicznym tekście z zakresu disability studies i teorii queer, Robert McRuer pisze o zderzeniu sposobów pisania tekstów akademickich $\mathrm{z}$ przedmiotem ich zainteresowania: „w jaki sposób uznać doświadczenia będące w centrum naszego opisu i pochodzące zarówno $\mathrm{z}$ akademickich, jak i nieakademickich wspólnot i dla których tworzenie tekstów (we wszystkich znaczeniach tego słowa) jest ewidentnie niesforna i nieuporządkowaną praktyką kulturową?"11. McRuer argumentuje, że studia o niepełnosprawności oraz teoria queer niosą ze sobą możliwość „,rozbicia” dotychczasowych zasad tworzenia tekstów: ciała niespełniające społecznych norm mogą wymagać nowych sposobów opisywania. „Dziwaczne” ciało żąda niekonwencjonalnie przeprowadzonej analizy. Akademia, a wraz z nią czasopisma naukowe, uznają jeden sposób pisania tekstów; sposób ten wymaga kompetencji, wiedzy i wieloletniego treningu. Recenzja ta nie odbiega daleko od owych rygorów: omawiam najważniejsze - w mojej ocenie - teksty, które się w niej znalazły, tworzę zdania w dość formalnym języku (choć staram się unikać żargonu, ale nie stanowiłby on raczej minusu), cytuję obficie innych akademików i akademiczki (szczególnie jak na tak krótki tekst), wpisuję książkę w szerszy kontekst. Recenzuję antologię, w której znajdują się teksty próbujące rozsadzić pewien sposób myślenia, a za tym i pisania o niepełnosprawności, mimo iż sama w zastanej akademickiej formule pisania

11 R. McRuer, Crip Theory: Cultural Signs of Queerness and Disability, New York University Press, New York-London 2006, s. 147. 
się odnajduję. Dlatego zastanawiam się, na ile studia o niepełnosprawności są zaczynem zmian nie tylko myślenia o ludzkim ciele i umyśle, ale także tworzenia tekstów na ten temat ${ }^{12}$. I na ile akademia, zainteresowana poszerzaniem granic swoich badań i stawianiem nowych pytań badawczych, jest również otwarta na alternatywnie skomponowane teksty. To drugie jest o tyle ważne, że aby istnieć w akademii, trzeba publikować, a żeby publikować, trzeba wiedzieć, jak napisać artykuł, który spełnia wszystkie rygory. I jest oczywiste, że nie wszystkie teksty w Disability and Dissensus rygory te spełniają, a zamiast nich wybierają crippowanie artykułu naukowego.

Nie każdy tekst w antologii spełnia wyśrubowane - i jakże relatywne - normy tekstu i nie każdy autor/autorka jest akademiczką. Do współpracy zaproszeni zostali aktywiści, scenarzyści, osoby, które odeszły z akademii. Ta wielogłosowość jest siłą książki, świadczy o różnorodności studiów o niepełnosprawności, wskazuje, że aby się nimi zajmować, nie trzeba w formalny sposób przynależeć do świata nauki. To istotne, bo przynależność do akademii dla osób z niepełnosprawnościami (w roli i studentów, i pracowników naukowych) jest strukturalnie utrudniona. Niepełnosprawność jest mile widziana, póki nie wymaga nadkruszenia status quo: kiedy funkcjonuje jako nowe zagadnienie do refleksji, ale niekoniecznie wtedy, gdy wymaga

12 Zagadnienie to, choć z innej strony, analizowałam w tekście Obietnica studiów o niepetnosprawności. Na marginesie ksiażki Jolanty Rzeźnickiej-Krupy ,, Społeczne ontologie niepetnosprawności” opublikowanym w ,Przeglądzie Kulturoznawczym” 2019, nr 41(3). wprowadzenia realnych zmian. Na stronie Uniwersytetu Warszawskiego można przeczytać, że usługi Biura dla Osób z Niepełnosprawnościami są dla tych, którzy liczą się ,z możliwością przeżycia frustracji w konfrontacji z ograniczeniami możliwego wsparcia lub w uzasadnionych przypadkach $-\mathrm{z}$ jego odmową"13 i są gotowi ,zaakceptować zasadę racjonalności dostosowań, tzn. zasadę sięgania po rozwiązania racjonalne ekonomiczne, skuteczne i wystarczające dla wyrównania Twoich szans na studiach w stosunku do Twojej grupy odniesienia, bez nakładania nieproporcjonalnego lub nadmiernego obciążenia na Uniwersytet" ". A więc dostęp bywa „nadmiernym obciążeniem” i istnieją racjonalne przesłanki, by w niektórych wypadkach go nie zapewniać. Uniwersytet Warszawski nie jest odosobniony w swej niechęci do zmiany funkcjonowania. W The Questions of Access: Disability, Space, Meaning kanadyjska badaczka z niepełnosprawnością Tanya Titchkosky analizuje podobnego rodzaju oświadczenia umieszczone na stronach uniwersytetów kanadyjskich ${ }^{15}$. Chodzi mi o ukazanie, że dostęp do świata akademickiego jest na każdym poziomie poważnie utrudniony dla osób z niepełnosprawnościami. Zgoda na eksperymentowanie $\mathrm{z}$ formułą pisania tekstów, zamieszczenie artykułów w antologii

13 Zob. https://bon.uw.edu.pl/dla-studentow/ kto-moze-skorzystac-z-uslug-biura/ (dostęp: 14.11.2020).

14 Ibidem.

15 Zob. T. Titchkosky, The Questions of Access: Disability, Space, Meaning, University of Toronto Press, Toronto 2011, s. 11-12. 
naukowej proponującej inny styl pisania jest więc formą dostępu.

Inną ciekawą stroną antologii jest to, że jest to chyba pierwsza tak duża publikacja wydana w języku angielskim, która oferuje wiele tekstów na temat Polski i polskich reprezentacji niepełnosprawności, nie rezygnując jednocześnie z perspektywy zachodniej (przede wszystkim anglosaskiej). Innymi słowy - antologia ta zderza znane, w pewien sposób kanoniczne, anglosaskie rozumienie niepełnosprawności z tekstami analizującymi i przybliżającymi zagranicznemu czytelnikowi polskie disability studies. Jest to ważne z kilku powodów: w krajach anglosaskich funkcjonuje wydana w 2016 roku publikacja Disability in Eastern Europe and the Former Soviet Union: History, Policy, and Everyday Life (red. Michael Rasell i Elena Iarskaia-Smirnova), ale nie zawiera ona żadnego tekstu o Polsce. W 2010 roku wydana została monografia Sarah Phillips Disability and Mobile Citizenship in Postsocialist Ukraine, w 2017 roku - Deaf in the USSR: Marginality, Community, and Soviet Identity, 1917-1991 autorstwa Claire Shaw, a w roku 2018 Dora Vargha opublikowała Polio across the Iron Curtain: Hungary's Cold War with the Epidemic. Podobnej monografii - na rynku międzynarodowym - dotyczącej Polski na razie brak. Tym samym Disability and Dissensus wprowadza z przytupem polskich autorów i autorki disability studies na globalną mapę studiów o niepełnosprawności. Oczywiście wprowadzenie to nie ogranicza się do przybliżenia nazwisk polskich badaczy i badaczek, a raczej jest szansą na pokazanie, w jaki sposób niepełnosprawność funkcjonuje w polskim dyskursie publicznym i kulturze.

Bardzo ważne jest, że w zamykającym tom tekście autorstwa Ojrzyńskiej i Wieczorka pt. Disability, Dis(sensual) Art, and the Politics of Representation autorka i autor omawiaja protest osób z niepełnosprawnościami oraz ich opiekunów i opiekunek w Sejmie w 2018 roku. Jest to zapewne jeden $\mathrm{z}$ pierwszych tak szczegółowych opisów protestu w języku angielskim. Fakt ten uważam za znaczący z kilku powodów: po pierwsze, polski protest jest częścią światowego ruchu walczącego o prawa obywatelskie osób z niepełnosprawnościami. Opisanie i zanalizowanie go po angielsku jest gestem partycypującym w konstruowaniu archiwum ruchu na rzecz praw osób niepełnosprawnych, przyczynia się do ukazania zróżnicowania ruchu, strategii walk i formułowania celów. Poza tym analiza ta pozwala zadać pytanie, jak polski ruch sytuuje się wobec np. ruchu amerykańskiego, brytyjskiego czy niemieckiego ${ }^{16}$, i zastanowić się, na ile polska specyfika kraju postsocjalistycznego ma wpływ na kształt protestu. Poszłabym zresztą dalej w kwestii analizy Ojrzyńskiej i Wieczorka, a także pozostałych autorów i autorek tekstów dotyczących polskich reprezentacji niepełnosprawności, i spytała wprost: co widać z peryferii (a czego nie widać z centrum)? Wyrosłe z aktywizmu studia o niepełnosprawności narodziły się i funkcjonują przede wszystkim w krajach anglosaskich, a dodatkowo

16 Zob. D. Herzog, Unlearning Eugenics: Sexuality, Reproduction, and Disability in Post-Nazi Europe, University of Wisconsin Press, Madison 2020 . 
kulturoznawcze czy też krytyczne studia o niepełnosprawności, do których odwołują się autorzy i autorki, to głównie domena badaczy i badaczek amerykańskich, jak więc doświadczenia peryferyjne zmieniają, czy też niuansują zachodnie rozumienie niepełnosprawności? Jakiego rodzaju napięcia się uwydatniają, gdy zderza się - jak robią to Ojrzyńska i Wieczorek - koncepcje wypracowane na gruncie anglosaskim i polskie reprezentacje niepełnosprawności?

Zamieszczenie tekstu traktującego o proteście w Sejmie w 2018 roku i jego reprezentacjach w dyskursie publicznym w tomie dotyczącym kulturowych reprezentacji przypomina o jeszcze jednej ważnej kwestii: reprezentacja, jak i jej interpretacja są polityczne. W Niezwyktych ciałach: przedstawieniach niepetnosprawności fizycznej $w$ amerykańskiej kulturze $i$ literaturze autorstwa Rosemarie Garland-Thomson autorka stawia tezę, iż „reprezentacja odpowiada za nadawanie ciałom znaczenia"17, a owe znaczenia nigdy nie są neutralne, a właśnie polityczne ${ }^{18}$. I tego, oczywiście, dotyczy zarówno artykuł Disability, Dis(sensual) Art, and the Politics of Representation, jak i pozostałe zamieszczone w antologii teksty. W tym sensie wydaje się, że Disability and Dissensus podąża za myślą

17 R. Garland-Thomson, Niezwykte ciala: przedstawienia niepetnosprawności fizycznej $w$ amerykańskiej kulturze i literaturze, przeł. N. Pamuła, Fundacja Teatru 21, Warszawa 2020, s. 38.

18 Książki Rosemarie Garland-Thomson $\mathrm{Ga}$ pienie sie, czyli o tym, jak patrzymy i jak pokazujemy siebie innym oraz Niezwykte ciata: przedstawienia niepetnosprawności fizycznej $w$ amerykańskiej kulturze i literaturze niedawno ukazały się nakładem Fundacji Teatr 21.
Garland-Thomson i podchodzi do kultury jako przestrzeni rozgrywania napięć i konfliktów o charakterze politycznym. W Siostrze Outsiderce Audre Lorde zawarła słynną tezę, iż „nie zdemontujesz domu pana przy użyciu jego własnych narzędzi”"19 (oryg. ,the master's tools will never dismantle the master's house"), ale jeśli pomyśli się o narzędziach krytyki literackiej i kulturoznawczej jako o narzędziach pana - jako o dominujących metodach odczytywania tekstów - to są one podobne do tych, które Garland-Thomson wykorzystała w Niezwyklych ciałach, by zaproponować nowe odczytanie kanonicznych powieści amerykańskich. I analogiczny ruch starają się zrobić Ojrzyńska i Wieczorek oraz pozostali autorzy. Zresztą Garland-Thomson nie jest obecna $\mathrm{w}$ antologii jedynie jako inspiracja, występuje też jako współautorka - wraz z Ojrzyńską - tekstu otwierającego całą książkę Critical Disability Studies in the Humanities. Tym samym publikacja ustanawia ją jako swego rodzaju założycielkę krytycznych studiów o niepełnosprawności w badaniach humanistycznych i wskazuje na jej myśl (tę zarówno z Niezwykłych ciat, jak i późniejszych publikacji, np. z Gapienia się) jako kluczową dla całej antologii.

Oprócz Garland-Thomson ważni dla pozostałych autorów i autorek są także Sharon L. Snyder i David T. Mitchell, amerykańscy badacze disability studies, autorzy takich wspólnych publikacji jak: Cultural Locations of Disability,

19 Zob. http://codziennikfeministyczny.pl/audre-lorde-nie-zdemontujesz-domu-pana-przy-uzyciu-jego-wlasnych-narzedzi/ (dostęp: 17.10.2020). 
The Biopolitics of Disability: Neoliberalism, Ablenationalism and Peripheral Embodiment oraz Narrative Prosthesis: Disability and the Dependencies of Discourse. I właśnie ta ostatnia pozycja, a zarazem pierwsza w dorobku badaczy, jest często przywoływana w Disability and Dissensus (poza tym Snyder i Mitchell obecni są tu nie tylko jako przypis, ale także jako autorzy tekstu Disability Cinema: Charting Alternative Ethical Maps of Living on Film). A raczej przywoływana jest nie cała pozycja, a tytulowa kategoria „narracyjnej protezy”. Mackiewicz-Ziccardi i Goodley ją definiują:

[Mitchell i Snyder - przyp. N.P.] zauważają, że niepełnosprawność znajduje się wszędzie w kulturze popularnej, ale często jest przywoływana po to, by wyrazić coś na temat wartości, które dominują nasze codzienne życie. Niepełnosprawność staje się podporą; rekwizytem oddającym różnorakie stereotypy, co stwarza paradoksalną sytuację, w której społeczna niewidzialność osób niepełnosprawnych koresponduje z jednoczesną cyrkulacją wizerunków osób niepełnosprawnych w kulturze druku ${ }^{20}$.

W Narrative Prosthesis Mitchell i Snyder omawiają znane dzieła literatury zachodniej, np. Ryszarda III i Moby Dicka i pokazują, w jaki sposób niepełnosprawność funkcjonuje w nich jako metafora, ale nie jako doświadczenie materialne. Piszę o tym dlatego, że kategoria „narracyjnej protezy” pojawia się w Disability and Dissensus często, a jednocześnie tylko jeden artykuł A Dwarf - A Metaphor and a Body in

20 D. Goodley, M. Mackiewicz-Ziccardi, Critical Disability Studies ..., op. cit., s. 39.
Words and Images Agnieszki Izdebskiej - poświęcony jest wyłącznie literaturze (tekst Disability and Its Doubles: The Conflicting Discourses of Disability in Susan Nussbaum's "No One as Nasty" Edyty Lorek-Jezińskiej dotyczy sztuki teatralnej). Kulturowe reprezentacje niepełnosprawności omawiane są w Disability and Dissensus na przykładzie filmów, seriali i teatru, co rodzi ciekawe pytanie: czy literatura nie jest głównym polem (albo po prostu jednym z głównych pól) tworzenia i kontestowania reprezentacji niepełnosprawności? Czy kino, telewizja i teatr oferują możliwość nawiązania bliższej relacji z odbiorcą (może nie są do tego stopnia co literatura zaklęte w języku?), a więc i kształtowania jego rozumienia niepełnosprawności? Nie znam odpowiedzi na te pytania, ale dobór tekstów, jak i zastosowanych narzędzi - pochodzących ze studiów literaturoznawczych, ale użytych do analizy innego rodzaju tekstów kultury - budzi ciekawość i wskazuje na interdyscyplinarność studiów o niepełnosprawności. $\mathrm{W}$ jeszcze większym stopniu nieobecne są w tomie sztuki piękne (oprócz przywołanego we wstępie muralu i tekstu Małgorzaty Sugiery, który częściowo analizuje malarstwo). Ale chodzi mi tu nie tyle o wyliczanie nieobecności, ile o zadanie pytania (niepojawiającego się w publikacji) o to, co nieobecność sztuk pięknych i literatury mówi na temat tego, które reprezentacje niepełnosprawności trafiają do publiczności oraz które kształtują jej wyobrażenia na temat niepełnosprawności. Inaczej mówiąc, które przestrzenie są istotne $\mathrm{w}$ wytwarzaniu 
znaczeń dotyczących nienormatywnych ciał według autorów i autorek tomu ${ }^{21}$.

Książka ta traktuje więc o splocie kultury i niepełnosprawności. Jest o tym, że analiza kulturoznawcza staje się analizą o wydźwięku politycznym, a niepełnosprawność sama w sobie jest kondycją czy też doświadczeniem politycznym. Ale jest także o pęknięciu między studiami o niepełnosprawności jako perspektywą akademicką a ruchem aktywistycznym walczącym o prawa osób z niepełnosprawnościami. Pęknięcie to było zapewne niezamierzone przez redaktorów, niemniej jest frapujące i warte poruszenia. W tekście wieńczącym całość, Disability, Dis(sensual) Art, and the Politics of Representation, Ojrzyńska i Wieczorek piszą, iż protest z 2018 roku był polityczny, mimo iż jego organizatorzy, a więc osoby z niepełnosprawnościami, nie podpisaliby się pod takim zdaniem: ,w przeciwieństwie do tego, co mówią organizatorzy, jest oczywiste, iż warszawski protest był głęboko polityczny"22. I to, co mnie w tym zdaniu, jak i postawie redaktorów interesuje, to pytanie, czemu badacze i protestujący, w oczywisty sposób sojusznicy, przyjmują tak odmienne interpretacje owego wydarzenia. Zakładam, że chodzi o inną definicję ,,polityczności”, ale

21 Jest to o tyle interesujące, że np. w latach 90. XX wieku polscy artyści należący do tzw. nurtu ,polskiej sztuki krytycznej” chętnie odwoływali się do niepełnosprawności w swoich pracach; np. Justyna Lipko-Konieczna pisała o wykorzystywaniu niepełnosprawności w pracach Artura Żmijewskiego: http://www. dialog-pismo.pl/w-numerach/niepelnosprawnosc-w-trybach-sztuki-krytycznej (dostęp: 17.10.2020).

22 Disability and Dissensus..., op. cit., s. 246. mam wątpliwość, czy ta odpowiedź jest zadowalająca. Pytanie to prowadzi mnie do kolejnego: jak badacze i badaczki disability studies mogą i pisać, i formułować swoje refleksje, by wyrażać idee ruchu walczącego o prawa osób z niepełnosprawnościami? Redaktorzy tomu nie poruszają tego tematu i nie uważam, że to źle, ale ich tekst skłania mnie do refleksji nad tym, na ile badacze studiów o niepełnosprawności mają za zadanie te idee wyrażać albo czy - zajmując się tą dyscypliną - niejako automatycznie to robią. Gdzie jest granica między studiami o niepełnosprawnościach a aktywizmem? Czy w każdym tekście ustanawiana jest od nowa? I czy jedność poglądów jest wartością albo kiedy nią jest (a kiedy brak spójności okazuje się bardziej twórczy)? Zadaję te pytania, bo antologię Disability and Dissensus interpretuję jako książkę napisaną właśnie z pozycji sojuszniczych, a ich autorów i autorki traktuję zarówno jako badaczy, jak i sojuszników.

\section{Bibliografia}

Garland-Thomson R., Niezwykte ciała: przedstawienia niepetnosprawności fizycznej $w$ amerykańskiej kulturze i literaturze, przeł. N. Pamuła, Fundacja Teatru 21, Warszawa 2020.

Goodley D., Disability Studies: Interdisciplinary Introduction, SAGE Publications, London 2010.

Goodley D., Mackiewicz-Ziccardi M., Critical Disability Studies: Sketches from Poland and the UK [w:] K. Ojrzyńska, M. Wieczorek (red.), Disability and Dissensus: Strategies of Disability Representation and Inclusion in Contemporary Culture, Brill, Leiden-Boston 2020. 
Herzog D., Unlearning Eugenics: Sexuality, Reproduction, and Disability in Post-Nazi Europe, University of Wisconsin Press, Madison 2020.

McRuer R., Crip Theory: Cultural Signs of Queerness and Disability, New York University Press, New York-London 2006.

Ojrzyńska K., Wieczorek M., Disability, Dis(sensual) Art, and the Politics of Representation [w:] K. Ojrzyńska, M. Wieczorek (red.), Disability and Dissensus: Strategies of Disability Representation and Inclusion in Contemporary Culture, Brill, Leiden-Boston 2020.

Ojrzyńska K., Wieczorek M. (red.), Disability and Dissensus: Strategies of Disability Representation and Inclusion in Contemporary Culture, Brill, Leiden-Boston 2020.
Pamuła N., Obietnica studiów o niepetnosprawności. Na marginesie książki Jolanty Rzénickiej-Krupy ,, Społeczne ontologie niepetnosprawności”, „Przegląd Kulturoznawczy” 2019, nr 41(3).

Siedlecka-Dorosz W., "and we all”: The Phenomenon of Theatre 21 [w:] K. Ojrzyńska, M. Wieczorek (red.), Disability and Dissensus: Strategies of Disability Representation and Inclusion in Contemporary Culture, Brill, Leiden-Boston 2020.

Titchkosky T., The Questions of Access: Disability, Space, Meaning, University of Toronto Press, Toronto 2011.

Wheeler E.A., HandiLand: The Crippest Place on Earth, University of Michigan Press, Ann Arbor 2019. 